\title{
A point prevalence study of 150 patients with idiopathic retinal vasculitis: 1 . Diagnostic value of ophthalmological features
}

\author{
ELIZABETH M GRAHAM,' M R STANFORD, ' M D SANDERS, ' EVA KASP, ' AND \\ D C DUMONDE ${ }^{2}$
}

From the Departments of ${ }^{1}$ Medical Ophthalmology and ${ }^{2}$ Immunology, United Medical and Dental Schools of Guy's and St Thomas's Hospitals, St Thomas's Campus, London SE1 7EH

SUMmaRY This paper describes the ophthalmological features of 150 patients with idiopathic retinal vasculitis, 67 of whom had isolated retinal vasculitis (RV) and 83 had RV associated with systemic inflammatory disease $(\mathrm{RV}+\mathrm{SID})$. The diagnosis of retinal vasculitis was made by ophthalmoscopy and fluorescein angiography, and patients with any identifiable cause (infection, ischaemia, or malignancy) were excluded from the study. Patients with isolated RV tended to have peripheral vascular sheathing, macular oedema, and diffuse capillary leakage. Those with RV accompanying Behçet's disease often had branch vein retinal occlusions and retinal infiltrates together with macular oedema and diffuse capillary leakage; the retinal infiltrates were pathognomonic for Behçet's disease. In sarcoidosis the retina typically showed features of periphlebitis associated with focal vascular leakage. Patients with uveomeningitis, multiple sclerosis, arthritis, or systemic vasculitis showed diffuse retinal capillary leakage associated with a mixture of the other features. Poor visual function was particularly associated with macular oedema and branch vein retinal occlusion, while the retina appeared to 'withstand' the impact of vascular sheathing, periphlebitis, or neovascularisation alone. Within the limitations of a point prevalence study it was concluded that different patterns of retinal vasculitis occur in different systemic inflammatory diseases, and that in isolated retinal vasculitis there is a particular association between peripheral vascular sheathing, macular oedema, and diffuse capillary leakage. In Part 2 we describe the results of examining the sera of these patients for the presence of antiretinal antibodies and circulating immune complexes.

Retinal vasculitis is a sight-threatening inflammatory eye disease whose aetiology and pathogenesis remain obscure. It may occur as a complication of infective, neoplastic, or degenerative disorders, in association with systemic inflammatory diseases (for example Behçet's, sarcoidosis) or as an isolated phenomenon. The ophthalmological features consist of cells in the vitreous accompanied by involvement of retinal vessels: the retinal veins are most commonly affected, and sheathing of the postcapillary venules frequently

Correspondence to Dr E M Graham, Department of Medical Ophthalmology, St Thomas's Hospital, London SE1 7EH. occurs together with evidence of diffuse capillary leakage on fluorescein angiography. As the retinal capillaries are frequently involved, there is loss of integrity of tight junctions between capillary endothelial cells which results in macular oedema and consequently visual loss. In contrast the retinal arterioles are rarely affected, except in advanced cases, where arteriolar occlusion is characteristically accompanied by multiple retinal vein occlusions.

The ophthalmological features of retinal vasculitis which occur in viral, ${ }^{12}$ parasitic, ${ }^{3}$ or fungal disease ${ }^{4}$ are easily recognised, as are those of an ischaemic or neoplastic nature,$^{56}$ where examination of the eye 
frequently provides information relevant to the clinical diagnosis of the underlying general medical disorder.

However, when retinal vasculitis accompanies systemic inflammatory disease, or occurs as an isolated phenomenon, the ophthalmological features appear to be less discriminatory. This study of 150 patients with retinal vasculitis was carried out primarily to determine whether any ophthalmological features could discriminate between patients with isolated retinal vasculitis (RV) and those with retinal vasculitis accompanying systemic inflammatory disease (RV+SID). A second objective was to determine whether any such ophthalmological features had predictive significance in terms of visual outcome.

\section{Patients and methods}

The patients were selected from those attending the Medical Eye Unit and the Inflammatory Eye Disease Clinic at St Thomas's Hospital. The majority were referred from hospitals elsewhere, but a few attended the Casualty Department. The diagnosis of retinal vasculitis was made on the ophthalmoscopic criterion of cells in the vitreous in association with involvement of retinal vessels (by ophthalmoscopy and/or fluorescein angiography). Patients with retinal vasculitis due to an identifiable cause (infection, ischaemia, or malignancy) were excluded from the study.

All patients had a full ophthalmological assessment by at least two observers. This included visural acuity corrected for distance and near, colour vision, and slit-lamp examination. The eyes were dilated in all patients and examined by indirect and direct ophthalmoscopy and a fundus lens. Colour fundus photography and fluorescein angiography were undertaken in most cases. Peripheral vascular sheathing was defined as sheathing of retinal vessels, whether or not associated with fluorescein leakage; sheathing was often seen in the peripheral retina where it was difficult to record photographically. Periphlebitis was defined as focal fluffy white cuffing of retinal veins; this occurred in association with focal leakage of fluorescein at these sites of inflammation.

The severity of the ocular inflammation in each patient was assessed by means of a points system previously described, ${ }^{7}$ and each patient was thereby allocated an ocular disease score. All patients had a full general medical examination and most had a chest $x$-ray and a Mantoux test. Systemic inflammatory diseases were identified by standard clinical criteria in Behçet's disease ${ }^{*}$ and systemic lupus erythematosus ${ }^{4}$ as well as by histological examination of lung or skin biopsies in sarcoidosis.
Table 1 Ophthalmological features of 67 patients with isolated retinal vasculitis

\begin{tabular}{lc}
\hline Feature & No. of patients \\
\hline Anterior uveitis & $23(33 \%)$ \\
Macular oedema & $40(60 \%)$ \\
Peripheral vascular sheathing & $43(64 \%)$ \\
Periphlebitis & $10(15 \%)$ \\
Retinal vein occlusion & $6(9 \%)$ \\
Retinal neovascularisation & $11(16 \%)$ \\
Retinal infiltrates & $0(0 \%)$ \\
Pigment epithelial disease & $22(3.3 \%)$ \\
\hline
\end{tabular}

ASSEMBIY ANDSTATISTICAL ANALYSIS OF

RESULTS

Details of all patients were entered on to a proforma. Statistical analysis was performed by $\chi^{2}$ tests and $95 \%$ confidence limits.

\section{Results}

One hundred and fifty patients fulfilled the criteria of retinal vasculitis for entry into the study. Two-thirds of the patients were under 40 years of age; $71(47 \%)$ were male and $79(53 \%)$ female. Sixty-seven patients had isolated retinal vasculitis (RV) and 83 had retinal vasculitis in association with systemic inflammatory disease (RV+SID).

FEATURES OF 67 PATIENTS WITH ISOLATED RV Twenty-seven patients in this group were male and 40 were female, and $72 \%$ of them were aged between 15 and 40 years. The ophthalmological features are sum-

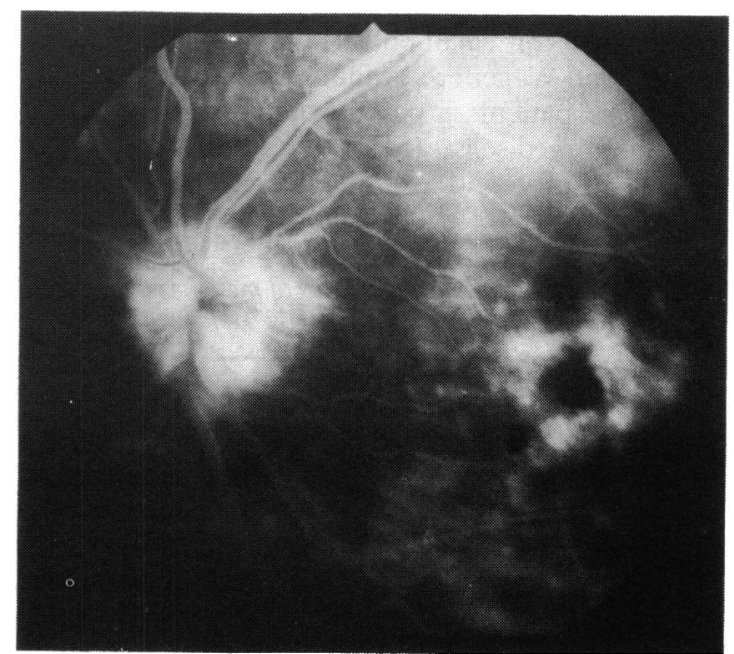

Fig. 1 Fluorescein angiogram in arteriovenous phase of left eye in 23-year-old girl with a two-year history of floaters and poor central vision. 
Table 2 Findings on fluorescein angiography in patients with isolated retinal vasculitis and retinal vasculitis associated with sarcoidosis and Behçet's disease

\begin{tabular}{llll}
\hline & $\begin{array}{l}\text { Isolated } R V \\
\text { (60 patients) }\end{array}$ & $\begin{array}{l}R V+\text { Behçet's } \\
(29 \text { patients) }\end{array}$ & $\begin{array}{l}R V+\text { sarcoidosis } \\
(14 \text { patients) }\end{array}$ \\
\hline Capillary leakage & $\begin{array}{l}47(78 \%) \\
\text { Capillary closure }\end{array}$ & $\begin{array}{l}29(100 \%) \\
14(23 \%)\end{array}$ & $\begin{array}{l}6(43 \%) \\
2(14 \%)\end{array}$ \\
\hline
\end{tabular}

marised in Table 1. The most prevalent findings were sheathing of peripheral retinal vessels, found in almost two-thirds of patients, and macular oedema, found in $60 \%$ (Fig. 1). One-third of the patients had atrophic pigment epithelial lesions. Retinal neovascularisation was observed in 13 patients $(16 \%)$ but was associated with retinal ischaemia in only five. Fluorescein angiography showed that, whereas the majority of patients had diffuse capillary leakage, only a quarter had capillary closure (Table 2 ). Thirtytwo patients had mild or moderate disease with a score of 10 or less, and 35 had pronounced or severe disease. These 67 patients generally retained good vision: two-thirds had a visual acuity of $6 / 18$ or better in at least one eye and only $22 \%$ had a visual acuity of worse than $6 / 18$ in both eyes.

FEATURES OF 83 PATIENTS WITH RV+SID

Forty-four patients in this group were male and 39 were female, and $61 \%$ of them were aged between 15 and 40 years. Thirty-nine patients had Behçet's disease, 17 had sarcoidosis, 11 presented with a uveomeningitic illness, nine had seronegative arthritis (in five, associated with HLA B27), two had systemic lupus erythematosus, two had glomerulonephritis, and three had polyarteritis nodosa, Crohn's disease, and Wegener's granulomatosis respectively.

In these patients a clinical diagnosis of systemic inflammatory disease (SID) was made after a full general history and examination, and laboratory investigations were confirmatory. Laboratory inves-



Fig. 2 Fluorescein angiogram of only eye of 35-year-old Caucasian with Behçet's disease with a one-week history of sudden loss of vision. The inferotemporal vein is irregular, tortuous, and dilated with staining of fluorescein. Macular oedema, capillary dilatation, and capillary closure are present in the affected quadrant.

tigations never revealed a systemic inflammatory disease in the absence of clinical signs.

The ophthalmological features differed according to the nature of the systemic inflammatory disease (Tables 2,3).

\section{BEHÇET'S DISEASE (39 PATIENTS)}

In this group 26 patients were male and 13 were female, and two-thirds were under 40 years of age. Twenty-eight patients were Anglo-Saxon, and there were also five patients from the Middle East, three Mongolian Asians, two West Indians and one Indian Asian. All 39 patients suffered with mouth ulcers and $29(74 \%)$ also had genital ulcers; in addition $18(46 \%)$

Table 3 Ophthalmological features of patients with retinal vasculitis associated with Behçet's disease, sarcoidosis, uveomeningitic syndrome and HLA B27-related arthritis

\begin{tabular}{|c|c|c|c|c|}
\hline & $\begin{array}{l}\text { Behçet's } \\
\text { (39 patients) }\end{array}$ & $\begin{array}{l}\text { Sarcoidosis } \\
\text { (17 patients) }\end{array}$ & $\begin{array}{l}\text { Uveomeningitic } \\
\text { syndrome } \\
\text { (11 patients) }\end{array}$ & $\begin{array}{l}\text { HLA B27-related } \\
\text { arthritis } \\
\text { (5 patients) }\end{array}$ \\
\hline Anterior uveitis & $19(49 \%)$ & $7(41 \%)$ & $4(36 \%)$ & $5(100 \%)$ \\
\hline Macular oedema & $26(67 \%)$ & $6(35 \%)$ & $8(73 \%)$ & $4(89 \%)$ \\
\hline Peripheral vascular sheathing & $14(36 \%)$ & $3(18 \%)$ & $5(45 \%)$ & 0 \\
\hline Periphlebitis & $9(23 \%)$ & $11(65 \%)$ & $3(27 \%)$ & 0 \\
\hline Retinal vein occlusion & $20(51 \%)$ & $2(12 \%)$ & $2(18 \%)$ & 0 \\
\hline Neovascularisation & $6(15 \%)$ & $3(18 \%)$ & $3(27 \%)$ & 0 \\
\hline Retinal infiltrates & $13(33 \%)$ & 0 & 0 & 0 \\
\hline Pigment epithelial disease & $8(21 \%)$ & $5(29 \%)$ & $1(9 \%)$ & 0 \\
\hline
\end{tabular}




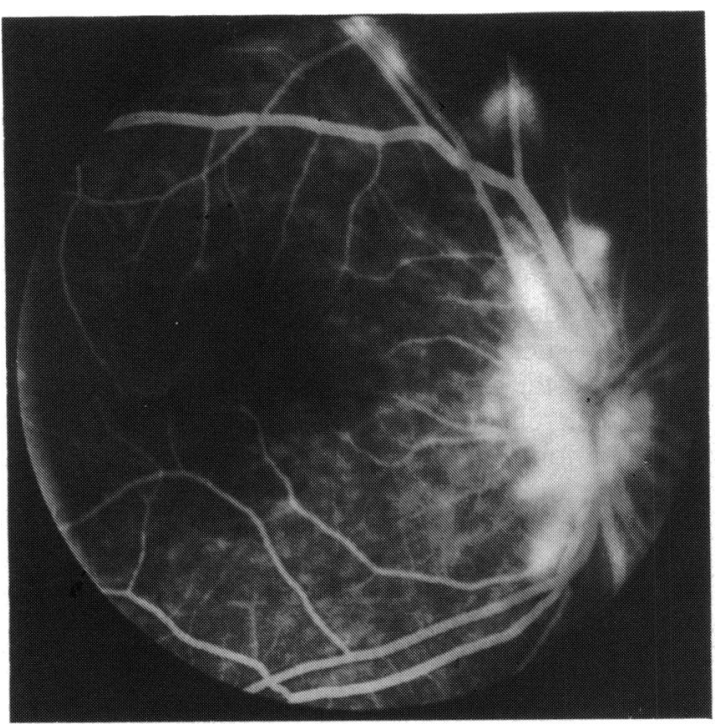

Fig. 3 A 20-year-old lad from Hong Kong presented with bilateral vitreous haemorrhages. He had new vessels on both optic discs, and fluorescein angiography did not show any associated capillary closure.

had arthritis, $20(51 \%)$ skin rashes, and $17(44 \%)$ thrombophlebitis. Seven patients $(18 \%)$ had central nervous system involvement, which was usually of the brain stem but also included optic neuritis and benign intracranial hypertension.

The most prevalent ophthalmological features

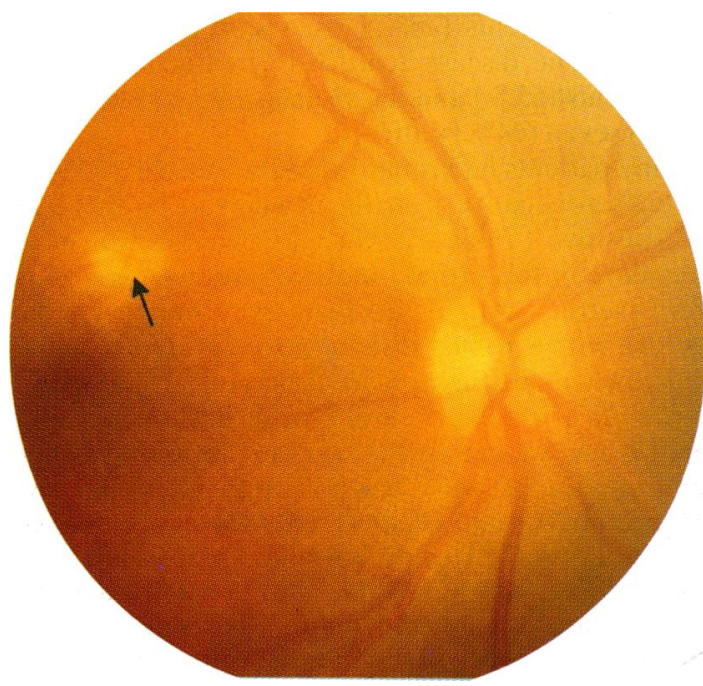

Fig. 4 The right fundus of a young Pakistani with Behçet's disease and active arthritis and orogenital ulceration. The view is poor due to vitreous haze. A retinal infiltrate (arrow) is present just above the fovea obscuring the vascular outlines.

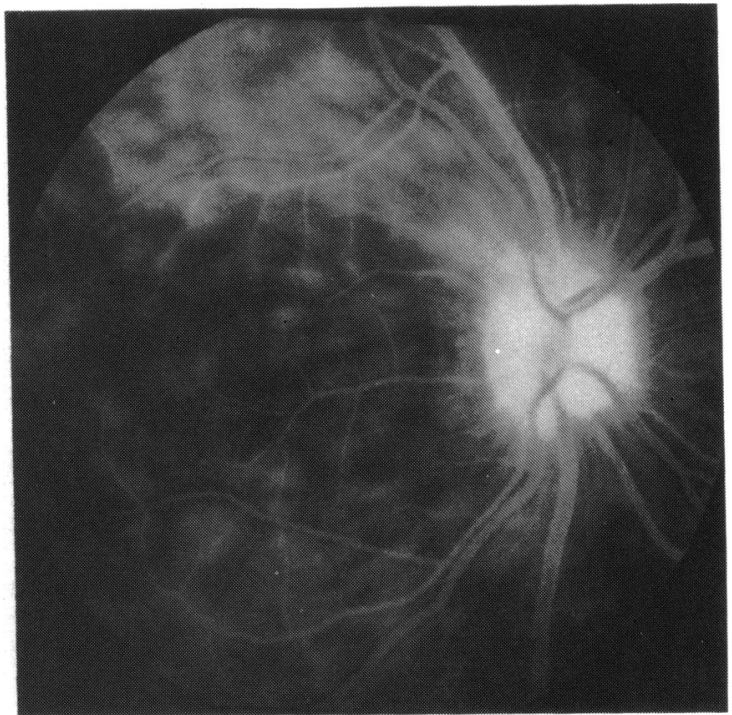

Fig. 5 Anteriovenous phase of fluorescein angiogram of right eye of young man with Behçet's disease. There is diffuse capillary leakage throughout the posterior pole.

were the presence of branch retinal vein occlusions, retinal infiltrates, and diffuse capillary leakage. Branch retinal vein occlusion occurred in 25 patients (64\%) (Fig. 2), and three of these subsequently acquired retinal new vessels. New vessels occurred in three other patients, during active inflammation, but in the absence of capillary closure (Fig. 3). Retinal infiltrates occurred in 13 patients $(33 \%)$. These

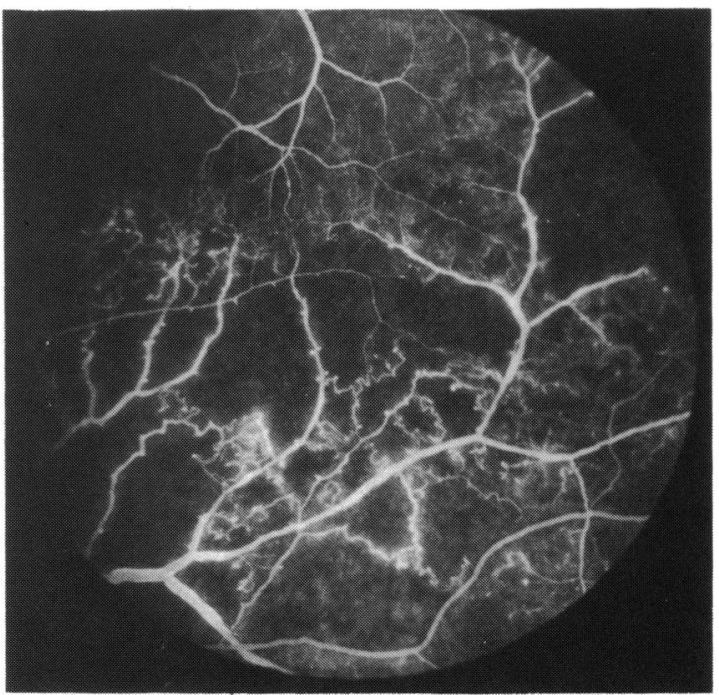

Fig. 6 Fluorescein angiogram of only eye of patient with Behçet's disease. Extensive capillary closure is present with collaterals and marked venous irregularity. 


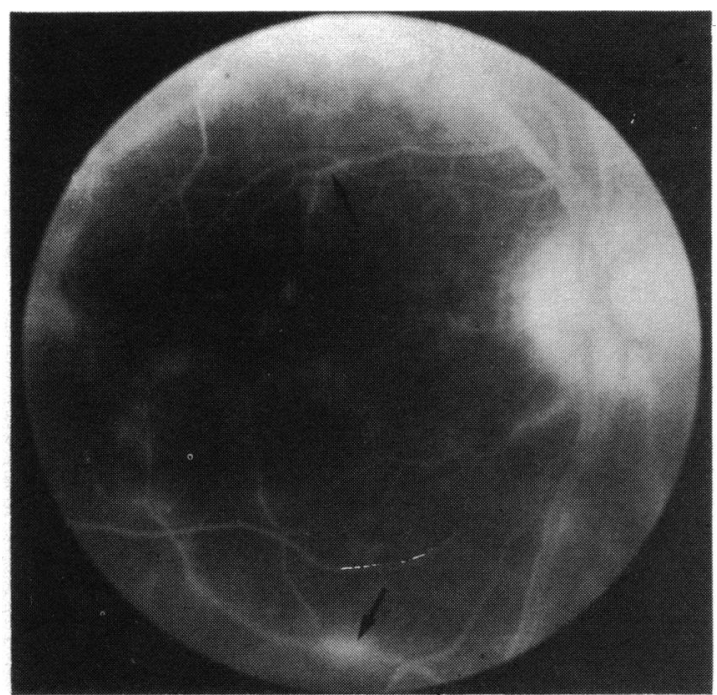

Fig. 7 Late fluorescein angiogram of young man who presented with hemiparesis, facial palsy, and uveitis. Focal leakage of fluorescein from the veins is present (arrows), with some capillary leakage and early macular oedema.

consisted of white lesions in the deep retinal layers, which appeared less fluffy than cotton-wool spots and less dense than retinal exudates ('hard cotton-wool spots') (Fig. 4). Retinal infiltrates were found to be unique to Behçet's disease and did not occur in other systemic inflammatory diseases. Focal atrophic pigment epithelial changes were observed in eight patients with retinal infiltrates and generally evolved as the retinal infiltrates resolved. Anterior uveitis occurred in 19 patients; however, hypopyon was seen in only five, and the other 14 patients had mild anterior uveitis. Fluorescein angiography showed diffuse capillary leakage in all 39 patients (Fig. 5; Table 3), thus emphasising the propensity for involvement of the posterior segment in Behçet's disease. Extensive capillary closure was demonstrated in those patients with recurrent vein occlusions (Fig. 6). The severity of ocular inflammation in this group was reflected by a disease score of more than 10 in 26 patients $(67 \%)$, a visual acuity of less than $6 / 18$ in one or both eyes in 32 patients $(82 \%)$ and a reduction of visual acuity to $6 / 18$ in both eyes in 18 of the patients $(46 \%)$.

\section{SARCOIDOSIS (17 PATIENTS)}

The group consisted of seven males and 10 females: 13 were Caucasian, three West Indian, and one Asian Indian; $11(65 \%)$ of the patients were under 40 years of age. The diagnosis of sarcoidosis was confirmed histologically in all cases: seven had positive Kveim tests and in the remainder the diagnosis was con- firmed by either lung or skin biopsy. Systemic problems included arthritis, erythema nodosum, and neurological disease, but severe pulmonary involvement was not a feature.

The distinguishing ophthalmological feature (Table 2) of this group was retinal periphlebitis associated with focal leakage of fluorescein, which occurred in 11 patients $(65 \%)$ (Fig 7). Only three patients from this group developed retinal new vessels, and these were in association with capillary closure in two of them. Two-thirds of the patients had disease scores of 10 or less, reflecting only mild or moderate retinal inflammation; only five patients $(23 \%)$ had significant reduction of visual acuity $(\leqslant 6 / 18)$ in one eye and only two patients $(12 \%)$ in both eyes.

\section{OTHER SYSTEMIC INFLAMMATORY DISEASES (27 PATIENTS)}

Eleven patients suffered from retinal vasculitis in association with a significant neurological disorder (uveomeningitis group). In seven patients this was confirmed as multiple sclerosis by a typical history of lesions of the central nervous system disseminated in time and space and by the presence of oligoclonal bands in the cerebrospinal fluid. In the other four the neurological illness could not be attributed to multiple sclerosis or sarcoidosis. The ophthalmological signs (Table 2) did not show any particular features which differentiated this uveomeningitis group from patients with either Behçet's disease or sarcoidosis, though a slightly greater proportion of the patients $(45 \%)$ developed peripheral sheathing and eight patients $(73 \%)$ lost vision from macular oedema. The disease score was greater than 10 in six patients (55\%) and the visual acuity was less than $6 / 18$ in seven $(64 \%)$ patients.

Nine patients had retinal vasculitis associated with severe seronegative arthritis, of which five were HLA B27-positive (Table 2). Macular oedema was most prevalent in this group, and two patients lost vision from serous retinal detachment. Similarly, the patient with Crohn's disease also suffered macular oedema and diffuse capillary leakage.

Retinal arteriolar occlusion with consequent capillary closure was seen in the two patients with systemic lupus erythematosus, and the patient with polyarteritis nodosa had a central retinal artery occlusion. The patient with Wegener's granulomatosis has been reported on elsewhere. "1" He had the non-sarcoidal form of the disease and ophthalmoscopic findings similar to those seen in sarcoidosis, with disc oedema, focal periphlebitis, and pigment epithelial lesions. The two patients with isolated glomerulonephritis developed peripheral vascular sheathing and macular oedema, but retinal vascular occlusion was not observed. 

acuity and ophthalmological features of 268 eyes affected by retinal vasculitis. The vertical bars represent the prevalence (in \%) of macular oedema, peripheral vascular sheathing, periphlebitis, retinal branch vein occlusion, and new vessel formation in this study. Open bars represent visual acuity 6/12 or better, hatched bars visual acuity 6/12 or worse. The figure shows that poor visual function was particularly associated with macular oedema and branch vein retinal occlusion $(p<0.001)$.
Fig. 8 Association between visual

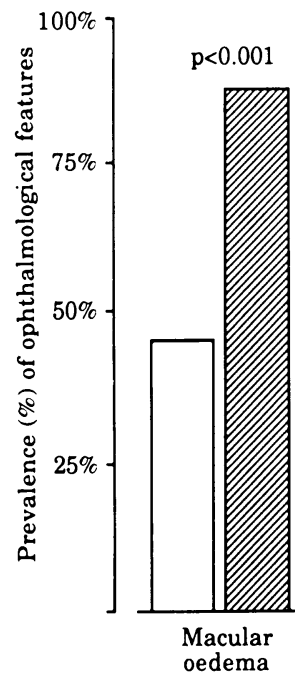

COMPARISON OF OPHTHALMOLOGICAI.

FEATURES BETWEEN PATIENT GROUPS

The most striking observation was that retinal infiltrates were found only in patients with Behçet's disease. Moreover, retinal branch vein occlusions were more frequently found $(\mathrm{p}<0.001)$ in Behçet's disease $(51 \%)$ than in either sarcoidosis $(12 \%)$ or isolated RV $(9 \%)$. However, periphlebitis was the most significant feature in sarcoidosis, where it occurred more often than in either isolated $R V$ $(\mathrm{p}<0.001)$ or in Behçet's disease $(\mathrm{p}<0.02)$ (Tables 1 and 2).

Peripheral vascular sheathing was a significantly prominent feature in patients with isolated $\mathrm{RV}$ $(64 \%)$ in comparison with those with Behçet's disease or sarcoidosis $(p<0 \cdot 001)$. Macular oedema was present in $60 \%$ of patients with isolated $\mathrm{RV}$ and in $54 \%$ of patients with $\mathrm{RV}+\mathrm{SID}$, where it was more frequent in Behçet's disease than in sarcoidosis $(p<0 \cdot 02)$. Macular oedema in Behçet's disease was particularly associated with poor vision in comparison with those patients with macular oedema due to either isolated RV $(\mathrm{p}<0.001)$ or sarcoidosis $(\mathrm{p}<0 \cdot 02)$. The patients with HLA B27-positive arthritis were the only group (albeit small) to have serous retinal detachments as a complication of their ocular inflammation (Table 2).

Fluorescein angiography revealed that patients with Behçet's disease had a higher prevalence of diffuse capillary leakage and capillary closure than those with sarcoidosis. In terms of capillary leakage, patients with isolated RV more closely resembled those with Behçet's disease than in sarcoidosis, while in terms of capillary closure patients with isolated RV more closely resembled the sarcoid group.
RELATIONSHIP BETWEEN OPHTHALMOLOGICAI. FEATURES AND VISUAL OUTCOME

Fig. 8 depicts the associations between the prevalence of five principal ophthalmological features of retinal vasculitis and visual acuity in 268 eyes (four patients each had one eyc enucleated, and in 28 patients only one eye was affected) regardless of whether patients had isolated RV or RV accompanying systemic inflammatory disease. One hundred and thirty-one eyes had a visual acuity of $6 / 12$ or better and 137 eyes had a visual acuity of $6 / 18$ or worse. Fig. 8 shows that macular oedema was associated with poor visual acuity $(\mathrm{p}<0 \cdot 001)$, and that retinal branch vein occlusion was also a significant factor in visual morbidity $(\mathrm{p}<0 \cdot 001)$. However, the prevalence of vascular sheathing (45-65\%), periphlebitis $(24 \%)$, and retinal neovascularisation $(12-13 \%)$ was not significantly different between eyes with good or bad visual acuity.

\section{Discussion}

This study of 150 patients was undertaken to determine whether any ophthalmological features of retinal vasculitis (RV) could distinguish patients with isolated RV from those with RV accompanying systemic inflammatory disorders (Behçet's disease, sarcoidosis, systemic lupus erythematosus); to identify the patterns of eye disease within these groups of patients; and to determine the relation of ophthalmological features to visual acuity. All the patients had cells in the vitreous and involvement of the retinal vessels, which differed in detail within the patient groups. Previous reports have described different patterns of retinal vasculitis accompanying different 
systemic inflammatory diseases, ${ }^{11-14}$ but this study is distinctive in that it directly compares the ophthalmological features between the specified patient groups.

The significant observations that we found were that branch retinal vein occlusion and retinal infiltrates emerged as features strongly associated with Behçet's disease; that periphlebitis was most prevalent in sarcoidosis; and that peripheral vascular sheathing, though common in all groups, was particularly prevalent in isolated retinal vasculitis (Tables 1 and 2). Retinal vasculitis was only rarely associated with severe seronegative spondylarthropathy, but when it occurred it presented as diffuse capillary leakage with macular oedema and serous retinal detachment without retinal vascular occlusion. Both ophthalmoscopy and fluorescein angiography revealed that the capillaries and the postcapillary venules were preferential sites of retinal inflammation in all these patients, whether or not the retinal vasculitis was associated with a systemic inflammatory disease. In contrast, vitreous cells and fluorescein leakage from postcapillary venules were rarely seen in patients with systemic vasculitis or Wegener's granulomatosis. In the systemic vasculitides the inflammatory reaction is known to predominantly affect the arterioles ${ }^{15}$; and, although retinal arteriolar occlusion may occur, it is usually due to local thrombus formation rather than to an active inflammation of the retinal vessel wall. ${ }^{16}$

The ophthalmological features would seem to reflect the pathological changes going on elsewhere in the body. In Behçet's disease the prominent clinical symptoms are related to the veins (for example, thrombophlebitis, vena caval obstruction), and the same situation seems to prevail in the eye. Characteristically, the vasculitis of Behçet's disease is accompanied by fibrinoid necrosis, exudation of plasma components, and leucocytic infiltrations; and inflammation of the retinal venules is more prominent than that of the retinal arterioles. In this study the patients with Behçet's disease had higher retinal disease scores and worse visual acuities than the patients in the other groups, which is a reflection of the impact of the disease on the retina. It seems likely that the poor visual prognosis in this group is due to the propensity for vein occlusion with consequent retinal ischaemia rather than simply to macular oedema, for macular oedema was a feature of all the groups, but the patients without Behçet's disease usually had better visual function. The severity of the retinal ischaemia in Behçet's disease is reflected in the low incidence of secondary neovascularisation (of $15 \%$ ), which is similar to that following ischaemic non-inflammatory arteriosclerotic branch vein occlusion. ${ }^{17}$

Periphlebitis was a particularly characteristic feature of retinal vasculitis accompanying sarcoidosis. A clinicopathological study by Gass and Olson ${ }^{18}$ has revealed invasion of the retinal vessel wall by inflammatory cells in these areas, often adjacent to non-caseating epithelioid cell granulomata, and it is likely that macrophage activation products are involved in the pathogenesis of chronic inflammation at these sites.

Eleven patients had retinal vasculitis in association with severe neurological disease, which was confirmed as multiple sclerosis in seven patients. All of these seven patients presented with floaters and did not develop neurological problems for a period ranging from six months to nine years after presentation with their ocular disease. In 1944 Rucker $^{19}$ described sheathing of the retinal veins in patients with multiple sclerosis, and other authors have since confirmed his findings. ${ }^{21}$ All Rucker's patients had normal retinal function, with a few vitreous cells and venous sheathing. However, our seven patients showed a variety of changes ranging from similar mild disease to severe retinal involvement with vascular occlusion, capillary closure, neovascularisation, and vitreous haemorrhage. To the ophthalmologist these latter patients are more akin to patients with sarcoidosis. However, pathological studies on patients with multiple sclerosis have shown infiltration of the retinal vessel wall with inflammatory cells, and identical changes have been found in the cerebral venules adjacent to plaques of demyelination in these patients. At sites of chronic inflammation both cerebral and retinal endothelial cells can express class II MHC products, ${ }^{21}$ and it is tempting to assume that a similar immunopathological process underlies both lesions. More detailed study of the retinal vascular changes in such patients with a uveomeningitic syndrome may well improve the understanding of the pathogenesis of multiple sclerosis.

Pathological studies of patients with retinal vasculitis are sparse, and there have not been any 'complete' necropsy reports of such patients. At the present time it is not possible to prove that isolated retinal vasculitis is indeed 'isolated', though all clinical investigation would support this presumption.

Within the limitations of a point-prevalence study examination of these 150 patients has shown that different patterns of retinal vasculitis occur in different systemic inflammatory diseases and that, in isolated retinal vasculitis, peripheral vascular sheathing, macular oedema, and diffuse capillary leakage seem to be associated with one another (Tables 1-3). The features of macular oedema and branch vein occlusion emerged as particularly associated with poor visual function (Fig. 8). In systemic inflammatory disease the patterns of retinal involvement 
would seem to reflect the nature of the pathological process in the rest of the body. However, all these systemic diseases are of an idiopathic nature, and further investigation of retinal involvement may yet identify aetiological or precipitating factors for these ill-understood clinical entities.

We thank all the referring ophthalmologists for allowing us to study their patients. Photographic assistance was provided by Mrs Gloria Cocking and secretarial assistance by Mrs Kay Mills and Miss Margaret Sceal.

This work was supported by grants from the Medical Research Council, the Iris Fund for Prevention of Blindness, the TFC Frost Charitable Foundation, the Sir Halley Stewart Trust, the Frances and Augustus Newman Foundation, and the Trustees and Research (Endowments) Committee of St Thomas's Hospital.

\section{References}

1 Egbert PE, Pollard RB, Gallagher JG, Merigan TC. Cytomegalovirus retinitis in immuno-suppressed hosts. II. Ocular manifestations. Ann Intern Med 1980; 93: 664-70.

2 Culbertson WW, Blumenkranz MS, Pepose JS, Stewart JA, Curton VT. Varicella zoster virus is a cause of the acute retinal necrosis syndrome. Ophthalmology 1986; 93: 559-68.

3 Perkins ES. Ocular Toxoplasmosis. Br J Ophthalmol 1973; 57: 1-17.

4 Griffin JR, Pettit TH, Fishman LS, Foos RY. Blood borne candida endophthalmitis. A clinical and pathological study of 21 cases. Arch Ophthalmol 1973; 89: 450-6.

5 Sarkies NJC, Shilling JS, Ross Russell RW. Fluorescein angiography in carotid diseases. Trans Ophthalmol Soc UK 1986; 105: 489-93.

6 Graham $\mathrm{E}$. Intraocular involvement of $\mathrm{T}$ and $\mathrm{B}$ cell lymphomas. Eye 1987; 1: 691-8.

7 Dumonde DC, Kasp E, Graham E, et al. Antiretinal autoimmunity and circulating immune complexes in patients with retinal vasculitis. Lancet 1982; ii: 787-92.

8 Lehner T, Barnes CG. Criteria for diagnosis and classification of
Behçet's syndrome. In: Lehner T, Barnes CG, eds. Behçet's syndrome: clinical and immunological features. London: Academic Press, 1979: 4-5.

9 Trimble R, Townes A. Robinson H, et al. Preliminary criteria for classification of systemic lupus erythematosus (SLE). Arthritis Rheum 1974: 17: 184-8.

10 Spalton DJ, Graham EM, Page NGR, Sanders MD. Ocular changes in limited forms of Wegener's granulomatosis. $\mathrm{Br} J$ Ophthalmol 1981; 65: 553-63.

11 Michelson JB, Chisari FV. Behçet's disease. Surv Ophthalmol 1982; 26: 190-203.

12 Sanders MD, Shilling JS. Retinal and choroidal and optic disc involvement in sarcoidosis. Trans Ophthalmol Soc UK 1976; 96: $140-4$.

13 Graham EM, Spalton DJ, Barnard RO, Garner A, Ross Russell RW. Cerebral and retinal changes in systemic lupus erythematosus. Ophthalmology 1985; 92: 444-8.

14 Welsh RB, Maumenee AE, Whelan HE. Peripheral posterior segment inflammation, vitreous opacities and oedema of the posterior pole. Arch Ophthalmol 1960; 64: 540-9.

15 Fauci AS. The spectrum of vasculitis. Clinical, pathologic immunologic and therapeutic considerations. Ann Intern Med 1978; 89: 660-76.

16 Shikano S. Ocular pathology of Behçet's syndrome. In: Monacelli M, Nazzaro P, eds. International Symposium on Behçet's disease, Rome 1965. New York: Karger, 1966: 111-36.

17 Hayreh SS, Rojas P, Podhajsky P, Montague P, Woolson RF. Ocular neovascularization with retinal vascular occlusion III. Ophthalmology 1983; 90: 488-506.

18 Gass JDM, Olson CL. Sarcoidosis with optic nerve and retinal involvement. Arch Ophthalmol 1976; 94: 945-50.

19 Rucker CW. Sheathing of the retinal veins in multiple sclerosis. Mayo Clin Proc 1944; 19: 176-8.

20 Engell T. Neurological disease activity in multiple sclerosis patients with periphlebitis retinae. Acta Neurol Scand 1986; 73: 168-72.

21 Wekerle $\mathrm{H}$. The lesion of acute experimental autoimmune encephalomyelitis. Isolation and membrane phenotypes of perivascular infiltrates from encephalitic rat brain white matter. $L a b$ Invest 1984; 51: 199-205.

Accepted for publication 25 May 1989. 